\title{
As instituições, produtores e produtos científicos do campo da moda no Brasil
}

Orestes Trevisol Neto

Mestre em Ciência da Informação -UFSC Professor no Curso de Biblioteconomia EaD da UNOCHAPECÓ e Bibliotecário - Universidade do Estado de Santa Catarina/Pinhalzinho.

Ligia Maria Arruda Café

Doutora em Linguística - Université Laval Canadá - Professora Associada do Departamento de Ciência da Informação e do Programa de PósGraduação em Ciência da Informação Universidade Federal de Santa Catarina.=

Edna Lúcia da Silva

Doutora em Ciência da Informação - UFRJ/IBICT -Professora Associada - Universidade Federal de Santa Catarina.

http://dx.doi.org/10.1590/1981-5344/2544

O interesse desta pesquisa está voltado para a análise da institucionalização científica no campo da Moda concentrando-se nos agentes, locais e processos de produção e comunicação científica. Os pressupostos que mobilizam o desenvolvimento desta pesquisa estão alicerçados na crença que os agentes, as instituições produtoras e a própria produção científica são responsáveis pela consistência científica do campo e pelo seu nível de institucionalização. A pesquisa teve como objetivo geral analisar a institucionalização científica do campo da Moda no Brasil. Possui caráter descritivo e exploratório, faz uma abordagem qualiquantitativa (mista) e utiliza técnica de pesquisa documental. O corpus da pesquisa foi constituído pelos dados retirados dos grupos de pesquisa em moda cadastrados no Diretório de Grupos de Pesquisa, dos Currículos Lattes dos pesquisadores, dos sites dos programas de pósgraduação, eventos e revistas científicas e demais documentos usados como fontes para coleta de dados. A cobertura temporal compreendeu os anos de 1988 a 2013. Na vertente da institucionalização social foram analisados os cursos de graduação e pós-graduação, as revistas, a associação de pesquisa, os eventos e os 
grupos de pesquisa desse campo. A importância da Associação Brasileira de Estudos e Pesquisa em Moda (ABEPEM) no processo de institucionalização social do campo ficou destacada. Na vertente da institucionalização cognitiva foram analisados os pesquisadores e a produção científica do campo. Nesse aspecto, foi possível detectar a existência de uma comunidade científica pequena e foi percebida a importância dada pelos integrantes dessa comunidade para a publicação de trabalhos em eventos, o que permite estabelecer uma relação direta entre institucionalização social e cognitiva nesse campo e a importância da comunicação científica no processo de institucionalização. Os resultados apontam indícios de institucionalização embrionária cognitiva e social do campo da moda no Brasil.

Palavras-chave: Institucionalização científica; Moda; Brasil.

\section{Institutions, producers and scientific production in the fashion field in Brazil}

The interest of this research is the scientific institutionalization of the fashion field focused on agents, places, production processes and scientific communication. The assumptions that move the development of this research are based in the belief that the agents, the producer institutions, and the scientific production are responsible for the scientific consistency of the field and for its institutionalization level. The general objective of this research is to analyze the scientific institutionalization of the Fashion field in Brazil. The research is descriptive and exploratory, using a qualitative and quantitative approach and a documentary research approach. The data is gathered in the research groups registered in the Brazilian Research Groups Directory, in the researchers résumé, from the graduate programs websites, from events, journals and other documents. The period analyzed was from 1988 to 2013. In terms of social institutionalization were analyzed the graduate and postgraduate educational courses, journals, research associations, events and research groups of the field. The importance of the Brazilian Association of Studies and Research in Fashion (ABEPEM) in the process of social institutionalization of Fashion field is highlighted. In terms 
of cognitive institutionalization the researchers and the scientific production of this field were analyzed. It was possible to detect that there is a small scientific community that believes that is important to published papers in events, which reveals a close relationship between the social and the cognitive institutionalizations of the field and the importance of scientific communication in the institutionalization process. The result shows evidence of embryonic cognitive and social institutionalization of the fashion field in Brazil.

Keywords: Scientific institutionalization; Fashion; Brazil.

Recebido em15.09.2015 Aceito em 12.04,2017

\section{Introdução}

A forte ligação da Ciência da Informação (CI) com os estudos da produção e comunicação científica, a partir da Segunda Guerra Mundial e em decorrência do aumento significativo do volume da literatura produzida, comunicada e publicada, tem sido evidenciada por diversos autores (ARAÚJO, 2009; PRÍNCIPE, 2013). Assim, estudos relacionados ao uso de fontes de informação, fluxo de informação, mediação e transferência da informação proliferam nesse campo (ARAÚJO, 2009). A vocação da CI para análises da comunicação na ciência envolvendo agentes, canais e produtos em diferentes campos do conhecimento é fato.

A comunicação científica formal surgiu como uma evolução do sistema particular e privado de comunicação realizado até então por meio de cartas, atas e memórias científicas. As correspondências entre os cientistas e as agremiações científicas originaram no século XVII as publicações científicas, voltadas para um público mais amplo, porém especializado (STUMPF, 1996; FREITAS, 2006).

A relevância da comunicação científica é reiterada por Mueller (2007, p. 128) quando expressa que a "comunicação desempenha papel central na ciência", o que vai ao encontro da afirmação já realizada por Ziman (1979, p. 24) de que "ciência é conhecimento público". No discurso de ambos subentende-se que no fazer da ciência, a comunicação é processo imprescindível, ou seja, a ciência e comunicação estão interligadas, são dependentes uma da outra.

A existência das instituições e da comunicação formal demonstra a organização interna do campo permitindo a construção de consenso científico e delimitam a zona de interesse, reforçando o desenvolvimento das comunidades científicas.

Para compreender a constituição de um campo científico ou como ocorre o desenvolvimento científico é necessário buscar fundamentos na sociologia da ciência e na filosofia do conhecimento. Nesta pesquisa, optou-se pela visão de Richard Whitley (1974) para analisar a 
institucionalização científica do campo da moda no Brasil, a partir das instituições, produtores e produtos científicos. Dessa forma, foram propostos como objetivo geral, analisar a institucionalização científica no campo da Moda no Brasil e como objetivos específicos: a) identificar as instituições formais do campo da moda no Brasil (cursos de graduação, pós-graduação, revistas, associação de pesquisa, eventos, grupos de pesquisa); b) identificar os pesquisadores do campo da moda; c) caracterizar a produção bibliográfica desses pesquisadores.

\section{A visão de Richard Whitley do desenvolvimento científico}

Whitley (1974) apresenta duas dimensões para o processo de institucionalização, denominando-as de institucionalização social e institucionalização cognitiva. As duas perspectivas estão entrelaçadas, mas nada impede que apresentem diferentes níveis de desenvolvimento, os quais o autor denomina de baixo ou alto nível de institucionalização.

A institucionalização cognitiva contempla os objetos de pesquisa, conceitos, teorias, técnicas, métodos, leis e problemas próprios de uma disciplina. Por sua vez, a institucionalização social refere-se às instituições formais que constituem o próprio campo, abrangendo a comunidade científica, por meio dos grupos de pesquisa, cursos de graduação e pósgraduação, periódicos, eventos/reuniões acadêmicos e associações/sociedades científicas. O desenvolvimento da dimensão cognitiva reflete na institucionalização social, e quando as estruturas formais do campo estão fortalecidas e consolidadas a tendência é que a dimensão cognitiva acompanhe esse movimento (WHITLEY, 1974).

O campo só irá conquistar um alto grau de institucionalização científica a partir do momento que seus pesquisadores, compartilharem de posturas comuns no que diz respeito aos objetivos, métodos e ideias. Esse estágio é alcançado por meio de dois aspectos da institucionalização cognitiva: o primeiro refere-se à clareza e ao consenso da área diante da relevância de seus problemas, dos métodos, técnicas e instrumentos utilizados, da definição e aceitabilidade de suas soluções; o segundo aspecto é definido pelo consenso oriundo da atividade desempenhada pelo cientista. Assim, obter reputação de seus pares deve ser uma meta a ser alcançada com critérios claramente estabelecidos (WHITLEY, 1974).

Áreas com alto nível de institucionalização cognitiva permitem prever o que o cientista irá pesquisar, que modelos e técnicas utilizará, que resultados pretende alcançar e quais as explicações serão aceitas pela comunidade. Um alto nível de institucionalização cognitiva denota um entendimento coerente acerca das normas estabelecidas em relação aos problemas e técnicas de pesquisa utilizadas. Existe um acordo entre a comunidade científica no que diz respeito ao universo e à forma de estudá-lo (WHITLEY, 1974).

Um baixo nível de institucionalização cognitiva refere-se a um baixo nível de ordem intelectual, pois reflete pouco compromisso e ausência de consenso. Nesse caso, o trabalho dos cientistas será desconexo e 
desarticulado, mesmos que eles tenham aderido valores básicos comuns e crenças sobre a natureza do empreendimento científico. O baixo nível de institucionalização tem consequência na atividade individual dos cientistas, sua identidade será pouco informativa sobre o que ele pesquisa e estuda, quais seus interesses ou que tipo de entendimento pretende obter. Nesse caso, o cientista deverá ser mais explícito, demonstrando o significado de suas atividades e justificando-as. Quanto mais o campo em que o cientista atua estiver institucionalizado, mais definidas são sua identidade cognitiva e sua área de atuação (WHITLEY, 1974).

O nível de institucionalização cognitiva constitui-se na medida em que os agentes concordam com o modo de apropriação do modelo no que tange a sua compreensão, extensão, articulação e elaboração. Portanto, o nível de institucionalização cognitivo nas especialidades e áreas de pesquisa está relacionado com a clareza, coerência e aplicabilidade de modelos teóricos e metodológicos (WHITLEY, 1974).

A institucionalização social refere-se à "criação e manutenção de estruturas formais que demarcam os membros da estrutura cognitiva". (WHITLEY, 1974, p. 75, tradução nossa). Essa dimensão também apresenta dois aspectos, o primeiro está relacionado com a organização interna do campo, diretamente ligado com a constituição e configuração dos periódicos científicos, grupos de pesquisa, cursos de graduação e pósgraduação, eventos científicos e profissionais, associações e sociedades científicas. O segundo diz respeito à integração social do campo com outras comunidades científicas, seu grau de legitimação/reconhecimento e locação de recursos. A institucionalização social representa o conjunto de características da área, compondo a identidade social, quando observada remete a uma visão total dos agentes que compõem o campo. Nesse âmbito relacionam-se as sociedades profissionais das quais os cientistas fazem parte, as redes de contato que são estabelecidas, os eventos científicos que participam, os cursos que atuam, os periódicos que avaliam e publicam seus artigos. Com base nesses elementos, o cientista é capaz de definir seu círculo social e profissional. Nas áreas não institucionalizadas existem problemas de configuração e na estrutura dos periódicos, eventos e reuniões profissionais, como consequência, têm-se poucos encontros anuais e periódicos com problema de consistência nas abordagens e dificuldades para se manterem em atividade. A indefinição e desorganização das fronteiras sociais são características de áreas não institucionalizadas (WHITLEY, 1974). Em um cenário de baixa institucionalização social, os pesquisadores formam grupos pequenos e coesos para estudo de problemas, valorizando nesse os contatos pessoais para obter informações e legitimação do próprio trabalho (WHITLEY, 1974).

A institucionalização social requer uma base cognitiva compartilhada entre os membros da comunidade científica, nítida o bastante para que suas ações reflitam na constituição da organização interna do campo. Whitley (1974) destaca que a institucionalização social pode ocorrer em um período mais tardio. 
Whitley (1974) entende que o reconhecimento acadêmico é um fator determinante no processo de institucionalização social e que os níveis de institucionalização cognitiva e social são processos de longa duração e sofrem influência do macrocosmo. Ao analisar a correlação entre a dimensão social e cognitiva de um determinado campo, deve-se estudar e compreender o contexto histórico, e as manifestações das instituições e agentes que compõem o próprio campo, atesta Whitley (1974).

\section{Procedimentos metodológicos}

Esta pesquisa possui caráter descritivo e exploratório, fazendo uma abordagem qualiquantitativa do problema, com uso de técnica de pesquisa documental. É uma pesquisa de caráter exploratório-descritiva, na medida em que se busca aproximação do problema e se procura descrever as relações, fatos e atores envolvidos na temática estudada referente ao campo da moda no Brasil.

O universo da pesquisa foi formado pelo conjunto das instituições, dos pesquisadores (doutores), dos cursos de graduação e pós-graduação, pela associação de pesquisa, pelos periódicos, e eventos científicos em moda do Brasil. O corpus da pesquisa foi constituído de registros retirados das seguintes fontes: Bases de dados: E-Mec e Web-Qualis; Plataforma Lattes: Diretório dos Grupos de Pesquisa do Conselho Nacional de Desenvolvimento Científico e Tecnológico (CNPq) e Currículo Lattes; Sites: Capes, Cursos, Associação, Revistas e Anais de eventos, etc.

A cobertura temporal compreendeu os anos de 1988 a 2013. Esse período registrou o nascimento dos cursos de graduação e pós-graduação em moda no Brasil. A amostra de pesquisadores foi composta por 349 doutores recuperados nos Grupos de Pesquisa e Currículo Lattes.

As variáveis analisadas quanto à institucionalização científica tiveram por base as vertentes propostas por Whitley (1974), ou seja, da institucionalização do ponto de vista social e cognitivo. Na variável da institucionalização social foram analisados os cursos de graduação e de pós-graduação, associações, revistas, eventos científicos e grupos de pesquisa, hoje estabelecidos no campo da moda no Brasil. Na variável da institucionalização cognitiva foi analisada a produção bibliográfica dos pesquisadores.

\section{A institucionalização social do campo da moda no Brasil}

No entendimento desta pesquisa considerou-se como partes das estruturas formais: os cursos de graduação, pós-graduação, revistas, eventos, associação e grupos de pesquisa do campo. Dessa forma, será realizada a descrição dos dados compilados que poderão fornecer indícios da institucionalização social do campo, bem como das relações existentes entre essa e a institucionalização cognitiva. 


\subsection{Institucionalização social: os cursos de graduação e pós-graduação em Moda no Brasil}

A situação atual dos cursos de graduação em moda no Brasil, conforme dados do $E-m e c$, é a seguinte: ao longo de quatro décadas foram criados 191 cursos tecnológicos, de licenciatura e bacharelado em moda. Desses 125 (65,44\%) cursos são tecnológicos, 112 estão em atividade, 5 estão em extinção e 8 foram extintos. Em nível de bacharelado foram criados 65 (34,03\%) cursos, 54 estão em atividade, 4 em extinção e 7 foram extintos. Em nível de licenciatura $1(0,52 \%)$ curso que está em extinção. Ressalta-se que o levantamento foi realizado por meio de pesquisa avançada come as expressões design de moda e moda, garantindo uma recuperação de todos os cursos desse campo.

É prudente lembrar que o interesse da pesquisa concentra-se em dados de institucionalização científica, por isso será realizada, a seguir, uma descrição mais detalhada dos cursos de graduação em moda bacharelado - existentes no Brasil em 2014.

Com base em dados levantados no E-mec ficou constatado que são 54 os cursos de graduação em nível de bacharelado, criados no período de 1974 a 2011. Desses, apenas 10 (18,51\%) cursos são ofertados por instituições públicas (estaduais e federais), os demais $44(81,48 \%$ ) são ofertados por instituições privadas de ensino. Desde o surgimento dos primeiros cursos de moda evidencia-se essa tendência, isto é, um interesse maior por parte do ensino privado na criação e manutenção desses cursos, como atesta Marinho (2002) e ficou comprovado nos dados levantados nesta pesquisa. Na esfera pública, o primeiro curso de moda implantado ocorreu no ano de 1994 na Universidade Federal do Ceará. O ano de 2004 foi o que teve maior incidência quanto à criação de cursos, sendo que 7 cursos foram implementados nesse ano, e em 2007 foram abertos 5. Nos anos de 2002, 2003, 2005 e 2008 implantaram-se 4 cursos em cada ano.

Os estados que concentram o maior número de cursos estão localizados na região sudeste e sul. O estado de São Paulo, além de ser o pioneiro nesse tipo de curso, é também o que apresenta o maior número de instituições com 15 cursos $(27,77 \%)$, na segunda posição está Santa Catarina com 10 cursos $(18,51 \%)$, Minas Gerais na terceira posição apresenta 8 cursos $(14,81 \%)$, Paraná possui 6 cursos $(11,11 \%)$ e Rio Grande do Sul, 4 cursos $(7,40 \%)$. Esses estados possuem pólos de confecção e têxtil, ou seja, têm forte presença da indústria. No estado de São Paulo, ocorrem muitos eventos de moda, por exemplo, a maior semana de moda do Brasil, o São Paulo Fashion Week (SPFW). Todos esses fatores estimulam a criação e manutenção de cursos nesse campo. A região Norte e Centro-Oeste apresentam a menor representatividade de cursos de moda, esse indicador tem relação com o desenvolvimento e a vocação econômica da região. As cidades com maior número de curso bacharelado em Design de Moda são: São Paulo (9), Belo Horizonte (4), 
Curitiba (3), Porto Alegre (3), Brusque (2), Goiânia (2) e Rio de Janeiro (2). As demais 29 cidades contam com apenas 1 curso.

No que tange aos cursos em nível de pós-graduação no campo da Moda, o mestrado de Moda Cultura e Arte do Centro Universitário SENAC - SP foi o primeiro mestrado específico em moda a existir no Brasil, entretanto, seu tempo de vida foi curto, a primeira turma ingressou no ano de 2005 e a última turma ingressou no ano de 2008, depois foi desativado (BONADIO, 2010). Esse foi o primeiro mestrado em moda da América Latina (PIRES, 2012). Igualmente, o Mestrado em Design da Universidade Anhembi Morumbi já foi composto por uma linha de pesquisa focada em moda, quando criado em 2006. A linha de pesquisa denominava-se "Design, Arte e Moda: Inter-Relações". Apesar da linha de pesquisa estar atualmente desativada, um número significativo de pesquisas foi concluído nesse programa (BONADIO, 2010).

Em 2011, a Universidade de São Paulo (USP) passou a oferecer o mestrado em Têxtil e Moda, até então, o único no país voltado em seus objetivos para o campo da moda (BONADIO, 2010; PIRES, 2012). "O objetivo principal do programa é a formação de professores, pesquisadores e profissionais de alto nível capazes de atuar na área têxtil e da moda com propostas inovadoras e diversificadas." (UNIVERSIDADE DE SÃO PAULO, 2014, p. 1). O corpo docente do programa é composto por 18 professores permanentes e 2 colaboradores. No que se refere às linhas de pesquisa, o programa tem duas linhas de pesquisa Materiais e Processos Têxteis e Projeto de Têxtil e Moda. A linha Projeto de Têxtil e Moda, mais voltada para o interesse desta pesquisa, busca estudar técnicas e metodologias do processo criativo, a prática do projeto, a modelagem, a aplicação no projeto do perfil antropométrico dos consumidores de vestuários, a sociologia da moda, os acessórios, aplicação da usabilidade e conforto do vestuário. Engloba "investigações que resultem na criação e desenvolvimento de produtos relacionados ao têxtil e à moda, tais como as mais recentes aproximações da criação e da tecnologia". (UNIVERSIDADE DE SÃO PAULO, 2014, p. 1).

Além do programa citado, foram identificadas 2 linhas de pesquisa focadas na temática moda em diferentes programas. O Mestrado em Design do Centro Universitário Ritter dos Reis (UNIRITTER) apresenta a linha de pesquisa Design, Moda e Inovação e o Mestrado em Artes, Cultura e Linguagens da Universidade Federal de Juiz de Fora (UFJF) possui a linha Arte, Moda: história e cultura. Ambos os programas são recentes, o de Design foi criado em 2009 e o mestrado em Artes, Cultura e Linguagens em 2013, os referidos programas foram classificados com conceito 3 pela Capes (2013).

Acredita-se que a institucionalização social tenderá a se fortalecer com a implantação de mais cursos de graduação em universidades públicas visto que essas tem mais vocação para o trabalho de pesquisa o que, consequentemente, implementará a criação de cursos de mestrado e doutorado nesse campo, visto que atualmente existe um programa de mestrado específico em moda no Brasil. A formação de pesquisadores fomentará a produção de conhecimento científico e incrementará os fluxos 
de informação entre a comunidade científica, reforçando assim a institucionalização social e, consequentemente, a cognitiva desse campo.

\subsection{Institucionalização social: os periódicos científicos, a associação e os eventos do campo da Moda no Brasil}

Os periódicos científicos refletem a vivacidade da área e conferem cientificidade ao campo. As associações e sociedades científicas constituem as estruturas sociais do campo (WHITLEY 1974), pois são entidades jurídicas que congregam os cientistas, estipulam as diretrizes da área e estimulam os eventos/encontros científicos e profissionais. Áreas institucionalizadas apresentam associações e sociedades científicas atuantes e coesas, operando na organização interna do campo (WHITLEY, 1974). Os eventos, seminários e conferências são locais propícios para os pesquisadores promoverem seus trabalhos e ampliarem suas redes de contato. Nesses ambientes são realizadas as trocas científicas informais mais significativas.

O campo da moda no Brasil possui 3 periódicos consolidados, que são as revistas Dobras, ModaPalavra E-periódico e Iara: revista de Moda, Cultura e Arte. A revista Dobras (ISSN 1982-0313), até então, da editora Estação das Letras e Cores, mostra no seu perfil que a revista tem a intenção de disseminar conhecimentos científicos e de caráter mais geral no campo da moda, abrigando colunas temáticas, artigos acadêmicos e entrevistas. Atualmente, são 16 os números publicados dessa revista entre 2007 e 2014, sendo em média 2 exemplares por ano. Destina-se aos "profissionais, pesquisadores, estudantes e interessados no conhecimento, estudo e pesquisa do universo da moda e design" (DOBRAS, 2014, p. 1). A revista ModaPalavra E-periódico (ISSN 1982615-x) lançada em 2008 surge a partir da transformação do livro ModaPalavra (ISBN 85-7474-229-5) editado desde 2002 a 2014 pelo Departamento de Moda da UDESC, o qual dissemina a produção científica dos seus docentes. A revista visa disseminar "contribuições das mais diferentes origens e mantendo a missão inicial de seu par, a de promover e difundir o conhecimento acadêmico, científico e consistente no campo." (SANT'ANNA, 2008, p. 2). A revista, a partir do número 7, passa a ser organizada em torno de dossiês e artigos variados (variata). Atualmente a revista já publicou 16 números, em média dois por ano. A Iara: revista de moda, cultura e arte (ISSN 1983-7836) foi concebida pelo extinto Programa de Pós-graduação em Moda, Cultura e Arte do Centro Universitário Senac em 2008 com vistas a demonstrar a importância da moda na perspectiva da cultura contemporânea (BUENO, 2008). A revista objetiva incentivar a produção e divulgação de artigos multidisciplinares, também "pretende refletir a grande diversidade teórica, bem como a metodológica, no campo da pesquisa em moda, cultura e arte, contemplando perspectivas das ciências humanas e das artes." (IARA, 2014 , p. 1). A revista já publicou 8 volumes com 2 números anuais.

A importância da existência de periódicos para a institucionalização social de um campo deve-se ao fato de os periódicos constituírem o 
principal canal de comunicação da ciência e atuarem como filtros de qualidade em todas as áreas do conhecimento, pois geralmente publicam o que é referendado pelos pares e, com isso, contribuem para a formação de consenso no campo.

O campo da Moda no Brasil tem uma associação de pesquisa atuante, a Associação Brasileira de Estudos e Pesquisas em Moda (ABEPEM) fundada em 2009. Sua fundadora e atual presidente é Kathia Castilho Cunha. A ABEPEM é uma organização que tem por finalidade "atender a todos a que ela se associem, independentemente da classe social, nacionalidade, sexo, raça, cor e crença religiosa". (ABEPEM, [2014], s. p.). Essa associação é responsável pela organização de grande parte dos eventos do campo, como: Colóquio de Moda (anual), Congresso de Iniciação Científica (anual), Fórum de Escolas de Moda (anual), Congresso Internacional de Moda e Design (bienal) e Seminário Internacional de Estudos e Pesquisa em Moda (anual) e Seminário Internacional de Estudos e Pesquisa em Consumo (anual) (ABEPEM, [2014], s. p.). A existência dos eventos, em si, colabora com a institucionalização social no momento que criam espaços de encontro e discussão das questões do campo e contribui com a institucionalização cognitiva na medida em que definem eixos temáticos e grupos de trabalho que são em tese norteadores da produção científica do campo.

No campo da moda no Brasil são realizados 8 eventos científicos conforme arrolados a seguir: Colóquio De Moda organizado pela ABEPEM, com início em 2005, já teve 10 edições; Fórum das Escolas de Moda organizado pela ABEPEM, com início em 2006, já teve 9 edições; Encontro Nacional de Pesquisas em Moda organizado por diversas entidades, com início em 2011, já teve 4 edições; Seminário Internacional de Estudos e Pesquisas em Consumo organizado pela ABEPEM, com início em 2011, já teve 3 edições; Seminário Internacional de Estudos e Pesquisas em Figurino organizado pela ABEPEM, com início em 2012, já teve 3 edições; Congresso Internacional de Moda e Design organizado pela ABEPEM, com início em 2012, já teve 2 edições; Congresso Científico Têxtil e de Moda organizado pela Associação Brasileira de Técnicos Têxtil, (ABTT) e USP com início em 2013, já teve 2 edições; Congresso Nacional de Iniciação Científica em Design de Moda, organizado pela ABEPEM, com início em 2014, já teve 1 edição. Nesses ambientes também são percebidas as relações de força e interesses dos membros da comunidade. Os cientistas renomados tendem a usufruir da sua visibilidade e reconhecimento diante dos pares - concorrentes, o que reforça ainda mais seu prestígio e poder sobre o campo de domínio (ZIMAN, 1979).

\subsection{Institucionalização social: os grupos de pesquisa em moda no Brasil}

Ao identificar os grupos de pesquisa em moda no diretório do Conselho Nacional de Desenvolvimento Científico e Tecnológico (CNPq), recuperou-se 42 grupos voltados para essa temática. Percebeu-se que os grupos apresentam distintas configurações temáticas, enquanto alguns têm a 
moda como objeto central de pesquisa, outros abordam a temática de forma periférica. Desse conjunto, $19(45,23 \%)$ grupos tinham no título o termo moda, enfocando assim, a concentração temática de interesse, já 14 (33,33\%) grupos apresentavam linhas de pesquisa com o termo moda, e nove $(21,42 \%)$ grupos registravam o termo nas palavras-chave e no texto informativo. Isso denota que nem todos os grupos possuem 0 mesmo nível de concentração no tema, o que diferencia seus interesses de pesquisa e suas abordagens. Grupos sólidos e comprometidos atuam no fortalecimento da dimensão cognitiva, por meio de suas contribuições teóricas, metodológicas e conceituais. Ao mesmo tempo fazem parte da dimensão social, uma vez que compõem a estrutura interna do campo (WHITLEY, 1974).

Optou-se por apresentar os grupos de pesquisa que apresentaram um enfoque maior na temática moda, considerando aqueles que continham o termo moda em seu nome. Assim, desses descreve-se o vínculo institucional, o número de integrantes doutores e a região procedente. Acredita-se que esses grupos são os responsáveis pelo desenvolvimento do campo: Tecnologias da moda e do têxtil: processos criativos para corpos do futuro (São Paulo, Universidade de São Paulo USP, 8 doutores); Arte, Design e Moda (São Paulo, Universidade Estadual de Campinas - UNICAMP, 7 doutores); Arte, Design e Moda ( São Paulo, Universidade de São Paulo - USP, 6 doutores); Moda, Comunicação e Cultura (São Paulo, Universidade Paulista - UNIP, 6 doutores) ; Moda na Cadeia Têxtil (São Paulo, Universidade de São Paulo - USP, 2 doutores); Moda, Imagem e Consumo (São Paulo, Universidade Anhembi Morumbi UAM, 1 doutor); Interfaces da Moda: saberes e discursos (Minas Gerais, Universidade Federal de Juiz de Fora - UFJF, 3 doutores); Design de Moda \& Tecnologia (Santa Catarina, Universidade do Estado de Santa Catarina UDESC, 10 doutores); Moda e sociedade (Santa Catarina, Universidade do Estado de Santa Catarina - UDESC, 5 doutores); Laboratório de História, Moda e Território - LHIMTE (Santa Catarina, Universidade Regional de Blumenau - FURB, 2 doutores); Promoda (Santa Catarina, Instituto Federal de Santa Catarina - IFSC, 1 doutor); Design de Moda (Paraná, Universidade Estadual de Londrina - UEL, 2, doutores); Arte, Moda e Design - Conexões Estéticas (Paraná, Universidade Paraense - UNIPAR, 1 doutor); Estudos Interdisciplinares em Moda (Paraná, Universidade Tecnológica Federal do Paraná - UTFPR, 1 doutor); Reflexões e projetos em design de moda (Paraná, Universidade Tecnológica Federal do Paraná - UTFPR, 1 doutor); PLURAL - Moda e Vestuário (Pernambuco, Universidade Federal Rural de Pernambuco - UFRPE, 7 doutores); Grupo de Estudos de Consumo de Moda (G-COMO) (Pernambuco, Universidade Federal de Pernambuco - UFPE, 4 doutores); Laboratório de Pesquisas Transdisciplinares sobre Moda (Pernambuco, Universidade Federal de Pernambuco - UFPE, 1 doutor); Linguagens, mídia e moda (MIMO) (Amazonas, Universidade Federal do Amazonas - UFAM, 1 doutor).

Tais grupos de pesquisa concentram-se nas regiões sul e sudeste, aspecto esse que tem relação com a consolidação dos cursos de 
graduação e pós-graduação nessas regiões e decorrentes também do desenvolvimento social, cultural e econômico dessas regiões no país. Pires (2002) e Marinho (2002) já indicaram a tradição da região sul e sudeste na criação dos primeiros cursos de moda em nível superior, fato esse comprovado com os dados desta pesquisa. Destaca-se que as instituições de ensino superior estadual e federal abrigam 15 grupos de pesquisa, dos 19 grupos listados acima. Enquanto o ensino privado concentra seus esforços nos cursos de graduação, as instituições públicas de ensino abrigam os grupos de pesquisa do campo. Observa-se que 4 instituições contam com mais de um grupo de pesquisa: UDESC, UFTPR e UFPE possuem 2 grupos de pesquisa, enquanto a USP apresenta 3 grupos. No entanto, os grupos que apresentam um maior número de pesquisadores doutores são: Design de Moda \& Tecnologia - UDESC (10 pesquisadores), Tecnologias da moda e do têxtil: processos criativos para corpos do futuro - USP (8 pesquisadores), Plural - Moda e Vestuário - (7 pesquisadores) UFRPE e Arte, Design e Moda - UNICAMP (7 pesquisadores).

A quantidade de doutores nos grupos de pesquisa é um indicador da maturidade do campo. Em média, um pesquisador leva em torno de 10 anos para concluir seus estudos e obter todas as titulações, por isso as áreas emergentes apresentam uma porcentagem maior de pesquisadores mestres, tendo em vista o tempo requerido para a formação de doutores. Contudo, a institucionalização social do campo científico da moda advém da sua organização interna e do amadurecimento da dimensão cognitiva (WHITLEY, 1974).

\subsection{Institucionalização cognitiva: características da produção do campo da moda e indícios de sua institucionalização cognitiva}

Toda a produção científica vai endossar a dimensão cognitiva do campo, independente de ser composta por publicações em artigos, livros ou trabalhos de evento. A estrutura desses documentos é diferente, mas o conteúdo sempre estará apoiado em correntes teóricas, técnicas, instrumentos, objetos, problemas e soluções que são particulares do campo (WHITLEY, 1974).

Da análise do currículo Lattes dos 349 pesquisadores doutores identificados como dedicados ao campo da moda no Brasil, observou-se que $144(41,26 \%)$ pesquisadores produzem efetivamente no campo, possuem mais de uma publicação. Com base na produção científica de moda, durante esses 26 anos analisados o campo contabilizou 2.163 produções científicas. Dessas, 1.365 (63\%) são trabalhos completos apresentados em eventos, 368 (17\%) são artigos científicos, $333(15 \%)$ são capítulos de livros e 97 livros (5\%). Mesmo com as tipologias da comunicação formal (artigo, livro, capítulo de livro) agrupadas observa-se que a comunicação semiformal (trabalhos em eventos) tem evidência nesse campo. 
$\mathrm{Na}$ categoria de artigos científicos, na qual os 349 doutores produziram e publicaram um total de 4.310 artigos no intervalo de 26 anos, apenas 368 são relacionados ao campo da moda. A incidência de publicação foi de 0 a 26 artigos por pesquisador, o que demonstra uma tímida produção científica, um pequeno número de pesquisadores com alta produção, acompanhado por um maior número de pesquisadores improdutivos. Nesse cenário, 241 (69,05\%) doutores não publicaram artigos, $44(12,60 \%)$ publicaram apenas um artigo e 64 (18,33\%) publicaram mais de um artigo. Os 368 artigos publicados em 26 de anos, representa a média de 0,45 artigos por ano, produzidos por 349 produtores, o que denota uma baixa produção de artigos publicados anualmente. A produção regular de artigos científicos reforça a institucionalização científica na medida em que são publicados os textos que passam pelo crivo do comitê de avaliação, aprovados em termos de conteúdo e forma, assim a dimensão cognitiva do campo vai sendo construída e consolidada. Campos cientificamente institucionalizados apresentam revistas bem organizadas e definidas em termos de escopo, temáticas e tipos de artigos aceitos, sendo possível ter precisão de quais são os interesses de pesquisas e as quais comunidades estão destinadas. Essas revistas respeitam sua periodicidade e contam com uma lista de avaliadores, sem apelar para o coleguismo na hora de avaliação (WHITLEY, 1975). Assim, os conteúdos das revistas são cruciais na construção da dimensão cognitiva do campo e reforçam o papel das revistas como expoentes de sua dimensão social.

$\mathrm{Na}$ categoria livros, os 349 pesquisadores publicaram um total de 1.158 títulos ao longo dos 26 anos, mas apenas 97 desses abordam a temática moda. A disparidade de publicação entre os pesquisadores na categoria de livro é significativa, uma vez que 305 (87,39\%) doutores não publicaram livros, $27(7,73 \%)$ doutores publicaram apenas um livro cada, e $17(4,87 \%)$ doutores publicaram mais de um livro. A concentração da produção de livros variou de 0 a 16. Observou-se que a maioria dos pesquisadores (33) publicou de 1 a 2 livros, apenas um publicou mais de 10 livros. Cabe ressaltar que nesta pesquisa os livros foram considerados na sua totalidade, isto é, sem qualquer distinção entre livros didáticos e técnicos. Dois fatores influenciam a publicação de livros no campo, o primeiro refere-se a recente academização do campo da moda, que inicia seu processo de constituição em 1988. O segundo diz respeito ao fato do sistema de avaliação científica apreciar a publicação de artigos, já que é o considerado o formato ideal para a ciência (ZIMAN, 1979). O fato de haver uma bibliografia internacional em livros consolidada há mais tempo influencia o consumo desse tipo de material, deixando em segundo plano a bibliografia nacional, pois, os títulos mais tradicionais do campo são de pesquisadores internacionais e distribuídos por grandes editoras.

No que se refere à produção de capítulos de livros, o cenário é semelhante aos demais tipos de publicações já apresentadas. Os 349 pesquisadores publicaram 2.443 capítulos de livros ao longo dos 26 anos, mas apenas 333 trazem uma abordagem relacionada à moda. Nesse caso, 251 doutores $(71,91 \%)$ não publicaram, $37(10,60 \%)$ publicaram apenas 
1 capítulo de livro e $61(17,47 \%)$ pesquisadores publicaram mais de 1 capítulo. A concentração da produção variou de 0 a 15 capítulos, apenas seis pesquisadores tiveram mais de 10 capítulos de livros publicados. É aceitável que exista um número maior de publicação de capítulos de livros, uma vez que esses podem ser compilações, reproduções ou novas versões de trabalhos já apresentados em congressos. Como também, percebe-se uma tradição do campo no que se refere à organização de coletâneas com a participação de diversos autores, no qual cada um escreve um capítulo.

A categoria de trabalhos em eventos foi a mais representativa. Os 349 doutores produziram 9.171 trabalhos em eventos, desse total, condizem com a temática moda 1.365 produzida ao longo dos 26 anos. A disparidade de produção nessa categoria também é expressiva, 191 $(54,72 \%)$ doutores não publicaram, 35 (10,02\%) publicaram apenas 1 trabalho e 123 (35,24\%) doutores publicaram 2 ou mais trabalhos. A concentração da produção de trabalhos em evento varia de 0 a 98 , sendo que somente 1 pesquisador publicou 98 trabalhos em eventos e 4 pesquisadores publicaram mais de 40 trabalhos. Tais pesquisadores caracterizam-se como os possíveis influenciadores de tendências de pesquisa no campo. A preferência por publicações em eventos pode ser motivada por muitos fatores. Os comitês editoriais dos eventos são mais flexíveis e abertos a novidades, visto que por meio da apresentação oral, - pesquisador consegue destacar aspectos importantes da pesquisa durante a exposição dos seus resultados, dirimir suas dúvidas e possivelmente receber feedbacks dos pares (MEADOWS, 1999).

A partir dos dados expostos, três aspectos são reafirmados. Primeiro que os 349 doutores identificados não apresentam a mesma dedicação a essa temática de pesquisa. Essa afirmação embasa-se entre a disparidade de publicações gerais produzidas quando comparada às publicações relativas ao campo da moda, o que levou a desconsiderar 165 (47\%) pesquisadores que não apresentaram nenhum vínculo estreito com 0 campo, ou seja, zeraram em número de publicações de moda. Da mesma maneira, 40 (11\%) pesquisadores foram desconsiderados por apresentar apenas uma publicação, fato que os deixou na categoria de novatos no campo nesta pesquisa e, por enquanto, com pouca contribuição efetiva ao campo. Dessa maneira, percebe-se a existência de um grupo de 144 (42\%) pesquisadores dedicados à temática, nos quais as publicações denotam que suas práticas de pesquisas são focadas e constantes no campo da moda. Esse grupo caracteriza-se como a comunidade científica do campo da moda e responsável pelo desenvolvimento e consolidação do consenso no campo, visto que uma comunidade científica é composta por todos que estudam e se especializam no ramo (ZIMAN, 1979) ou partilham um paradigma (KUHN, 2009).

A distribuição irregular da produção científica dos pesquisadores analisadores possui estreita relação com o efeito Mateus de Merton (2013), segundo essa teoria os mais produtivos tendem a publicar mais, uma vez que já possuem mais reconhecimento e condições para produzir 
e publicar. Em tese tais pesquisadores acumulam maior volume de capital científico e influenciam assim as estruturas do campo (BOURDIEU, 2004).

Os aspectos ressaltados nesta pesquisa contribuem para conhecer a realidade científica do campo da moda no Brasil, como também, demonstram a dinâmica e a relação existente entre as instituições, os agentes e seus constructos científicos.

\section{Considerações finais}

Nesta pesquisa, na vertente da institucionalização social foram analisados os cursos de graduação e pós-graduação, as revistas, a associação de pesquisa, os eventos e os grupos de pesquisa desse campo. Nessa perspectiva de análise, foi possível verificar a importância da ABEPEM no processo de institucionalização social desse campo e dos eventos promovidos por essa associação. Essa associação orienta o campo da Moda no Brasil ao estabelecer diretrizes e focos de atuação. É responsável por congregar os pesquisadores do campo, estimular/organizar os eventos acadêmicos e profissionais. Sua presidente, Kathia Castilho Cunha assume posição de destaque no campo da moda e tem forte atuação política no campo.

$\mathrm{Na}$ vertente da institucionalização cognitiva foram analisados os pesquisadores e a produção científica do campo e nesse aspecto foi possível detectar a existência de uma comunidade científica pequena e foi percebida a importância dada pelos integrantes dessa comunidade para a publicação de trabalhos em eventos, o que permite estabelecer uma relação direta entre institucionalização social e cognitiva nesse campo e a importância da comunicação científica no processo de institucionalização.

Os dados levantados e analisados também permitiram outras constatações. O desenvolvimento do campo da moda no Brasil está atrelado ao contexto econômico favorável e ao desenvolvimento regional, visto que as regiões que se destacam econômica e socialmente no país foram destacadas também nesta pesquisa, nos processos de institucionalização social e cognitiva desse campo. Os cursos de graduação, pós-graduação e grupos de pesquisa em Moda estão concentrados na região Sudeste e Sul. As instituições de ensino privadas oferecem maior parcela de cursos de graduação em nível bacharelado e as instituições de ensino estadual e federal abrigam em sua maioria os grupos de pesquisa do campo. O único mestrado em Moda vigente no Brasil até o ano de 2014 é oferecido pela USP e se denomina: Têxtil e Moda. De todos os programas de Pós-graduação em Design, apenas o mestrado da Uniritter apresenta uma linha de pesquisa voltada para a moda. Na região sul, a UDESC é responsável por um curso de graduação em Moda e é responsável pelo periódico Modapalavra, única publicação de responsabilidade de uma instituição pública de ensino. Observou-se que o campo é constituído por uma pequena comunidade científica, composta por 144 pesquisadores comprometidos com pesquisa de temas relacionados ao campo. Nesse aspecto, é preciso lembrar que o levantamento concentrou-se nos pesquisadores doutores, devido ao 
entendimento pré-estabelecido de que esses estariam mais comprometidos com o desenvolvimento de pesquisas $e$, consequentemente, seriam os responsáveis pelo desenvolvimento científico do campo. Nesse grupo existe uma pequena elite de pesquisadores produtivos e um grande número de pesquisadores com baixa produtividade científica, aspecto esse que corrobora alguns princípios da Lei de Lotka ${ }^{1}$ (LOTKA, 1926). O campo apresenta uma tendência pela preferência de canal de comunicação científica semiformal para disseminar suas pesquisas, uma vez que publicam mais trabalhos em eventos do que em artigos e em livros. Na categoria de comunicação científica formal, o campo publica mais artigos do que livros.

Diante dos dados apresentados, acredita-se que os objetivos propostos foram alcançados, resultando em um olhar macro do desenvolvimento do campo da moda no Brasil. A análise apurada dos resultados aponta indícios de institucionalização embrionária cognitiva e social do campo da moda no Brasil, embora não seja possível afirmar com exatidão o nível de institucionalização, visto que todas as instituições do campo foram implantadas muito recentemente, e é preciso mais maturidade para estimar se o campo apresenta baixo ou alto nível de institucionalização. Destaca-se que o campo apresenta todos os componentes necessários de uma disciplina científica, aspecto que o caracteriza como científico. Ao longo da última década é perceptível o seu desenvolvimento social e cognitivo, tendo em vista o aumento dos cursos de graduação, pós-graduação, da produção intelectual e na formação de novos pesquisadores.

Resta lembrar que essa configuração da institucionalização científica desse campo deve ser vista a partir das decisões metodológicas e dos recortes efetuados para o desenvolvimento desta pesquisa em termos de amostra e de abrangência dos dados.

\section{Referências}

ASSOCIAÇÃO BRASILEIRA DE ESTUDOS E PESQUISA EM MODA (ABEPEM). Quem somos. [2014]. Disponível em: $<$ http://www.abepem.com.br/index.php?option=com_content\&view=articl e\&id=8\&Itemid=9>. Acesso em: 30 dez. 2014.

ARAÚJO, C. Á. Correntes teóricas da Ciência da Informação. Ciência da Informação, Brasília, v. 38, n. 3, p. 192-204, set./dez. 2009.

BONADIO, M. C. A produção acadêmica sobre moda na pós-graduação stricto sensu no Brasil. IARA: revista de moda, cultura e arte, São Paulo, v. 3, n. 3, p. 54-146, dez. 2010.

BRASIL. Ministério da Educação. Sistema E-mec. 2014. Disponível em: <http://emec.mec.gov.br/>. Acesso em: 20 nov. 2014.

\footnotetext{
${ }^{1}$ Formulada em 1926, essa lei preconiza que em uma área de conhecimento a quantidade de autores que publicam dois artigos é igual a 1/4 do número de autores que publicam um artigo; autores que publicam três artigos correspondem a 1/9 dos que produziram somente um artigo; e $60 \%$ dos autores de um campo produz somente um artigo em toda a sua vida acadêmica.
} 
BOURDIEU, P. Os usos sociais da ciência: por uma sociologia clínica do campo científico. São Paulo: Editora UNESP, 2004.

BUENO, M. L. Editorial. IARA: revista de moda, cultura e arte, São Paulo, v. $1, \quad$ n. $1, \quad$ p. 1 , 2008. Disponível em: <http://www.iararevista.sp.senac.br/>. Acesso em: 30 ago. 2014.

COORDENAÇÃO DE APERFEIÇOAMENTO DE PESSOAL DE NÍVEL SUPERIOR (CAPES). Cursos recomendados e reconhecidos. 2013. Disponível em: <http://www.capes.gov.br/avaliacao/cursos-recomendados-e-

reconhecidos $>$. Acesso em: 30 set. 2013.

COLÓQUIO DE MODA, 11., 2015, Curitiba. Anais eletrônicos... Curitiba: ABEPEM, 2015. Disponível em: <http://www.coloquiomoda.com.br/abepem.php>. Acesso em: 1 jan. 2015.

CONGRESSO INTERNACIONAL DE MODA E DESIGN, 2., 2014, Milão. Anais eletrônicos... Milão: Politécnico di Milano, 2014. Disponível em: <https://www.cimode.polimi.it/index.php/cimode 2014/ cimode2014a/>. Acesso em: 1 jan. 2015.

CONGRESSO CIENTÍFICO TÊXTIL E DE MODA, 2., 2014, SÃO PAULO. Anais eletrônicos... São Paulo: SENAI, 2014. Disponível em: <http://www.contexmod.com.br/index.html>. Acesso em: 1 jan. 2015.

CONSELHO NACIONAL DE PESQUISA (CNPq). Sobre a Plataforma Lattes. 2013. Disponível em: <http://lattes.cnpq.br/>. Acesso em: 1 out. 2013.

CONSELHO NACIONAL DE PESQUISA (CNPq). Diretório dos grupos de pesquisa no Brasil. [2014]. Disponível em: <dgp.cnpq.br/buscaoperacional/>. Acesso em: 13 fev. 2014.

DOBRAS. São Paulo: Estação da Letras e Cores. 2014. Disponível em: <http://www.estacaoletras.com.br/revista_dobras.php>. Acesso em: 30 ago. 2014.

ENCONTRO NACIONAL DE PESQUISAS EM MODA, 4., 2014, Florianópolis. Anais eletrônicos... Florianópolis: UDESC, 2014. Disponível em: <http://www.ceart.udesc.br/enpmoda/>. Acesso em: 1 jan. 2015.

FREITAS, M. H. Considerações acerca dos primeiros periódicos científicos brasileiros. Ciência da Informação, Brasília, v. 35, n. 3, p. 54-66, set./dez. 2006.

IARA: revista de moda, cultura e arte. São Paulo: SENAC, 2014. Disponível em: <http://www.iararevista.sp.senac.br/. Acesso em: 30 nov. 2014.

KUHN, T. S. A estrutura das revoluções científicas. São Paulo: Perspectiva, 2009.

LOTKA, A. J. The frequency of distribution of scientific productivity. Journal of the Washington Academy of Sciences, v. 16, n. 12, p. 317-323, 1926. 
MARINHO, M. G. S. M. C. Moda: condicionantes sociais de sua institucionalização acadêmica em São Paulo. In: WAJNMAN, S.; ALMEIDA, A. J. de. (Org.). Moda, comunicação e cultura: um olhar acadêmico. São Paulo: Arte e Ciência/Núcleo Interdisciplinar de Estudos da Moda (NIDEM)/FAPESP, 2002. p. 13-26.

MEADOWS, A. J. A comunicação científica. Brasília: Briquet de Lemos, 1999.

MERTON, R. K. Ensaios de sociologia da ciência. São Paulo: Editora 34, 2013.

MODAPALAVRA E-PERIÓDICO. Florianópolis: UDESC/CEART, 2014. Disponível em: <http://www.revistas.udesc.br/index.php/ modapalavra>. Acesso em: 30 nov. 2014.

MUELLER, S. P. M. Literatura científica, comunicação científica. In: TOUTAIN, L. M. B. B. (Org.). Para entender a Ciência da Informação. Salvador: EDFBA, 2007. p. 125-144.

PIRES, D. B. A história dos cursos de design de moda no Brasil. Nexos, São Paulo, v. 6, n. 9, p. 1-13, 2002.

PIRES, D. B. Design moda e design de moda: linha do tempo do ensino no Brasil. Iara: revista de moda, cultura e arte, São Paulo, v. 5, n. 1, p. 190203, maio 2012.

PRÍNCIPE, E. Comunicação científica e redes sociais. In: SARITA, A. (Org). Fronteiras da Ciência da Informação. Brasília: IBICT, 2013. p. 196-216.

SANT'ANNA, M. R.. Editorial. Modapalavra E-periódico, Florianópolis, v. 1, n. $1, \quad$ p. $1,2008.2$ Disponível em: <http://www.ceart.udesc.br/modapalavra/ edicao1/index.php>. Acesso em: 30 ago. 2014.

STUMPF, I. R. C. Passado e futuro das revistas científicas. Ciência da Informação, Brasília, v. 25, n. 3, p. 383-386, set./dez. 1996.

WHITLEY, R. Cognitive and social institutionalization of scientific specialties and research areas. In: WHITLEY, Richard (Ed.). Social process of scientific development. London: Routledge, 1974. p. 69-95.

UNIVERSIDADE DE SÃO PAULO. Mestrado Acadêmico em Têxtil e Moda. São Paulo, 2014. Disponível em: <http://www.each.usp.br/ site/posprogramas.php?item=txm>. Acesso em: 20 dez. 2014.

ZIMAN, J. M. Conhecimento público. Belo Horizonte: Itatiaia; São Paulo: Ed. Univ. S. Paulo, 1979. 